\title{
Contrived publications and COVID-19 communication noise
}

\author{
Shahryar Sorooshian, ${ }^{1}$ Senthil Kumar ${ }^{2}$ \\ ${ }^{1}$ Department of Business Administration, University of Gothenburg, Sweden; ${ }^{2}$ Faculty of Industrial Management, Universiti \\ Malaysia Pahang, Malaysia
}

Dear Editor,

At present, effective antivirals against the coronavirus infection disease 2019 (COVID-19) do not seem to be available, and hence medical practitioners and governments are vying for any useful information on the treatment and management of this outbreak. Research journals have played their part by promoting COVID-19 research to ensure that the stakeholders have immediate access to adequate information. Some journals have fast-tracked the COVID-19 papers, and a few other journals have waived the publication fee to encourage sharing of experience from the developing countries. ${ }^{1}$ Special issues have been another option for some journals. These affirmative actions have helped in sharing vital information on the treatment and management of this pandemic.

However, reviewers are under tremendous pressure as the number of manuscripts increases on the one hand, and the turnaround time is decreasing, on the other hand. ${ }^{1}$ Next, there is an attempt to link every research to COVID-19 to fast track the publication and get the work published by class-leading journals.

Correspondence: Shahryar Sorooshian, Department of Business Administration, University of Gothenburg, Vasagatan1, 40530 Gothenburg, Sweden.

Tel.+46.31.7861463. E-mail: sorooshian@gmail.com

Key words: COVID-19; research; publication.

Contributions: the authors contributed equally.

Conflict of interests: the authors declare no potential conflict of interests.

Received for publication: 7 August 2020.

Revision received: 25 August 2020.

Accepted for publication: 25 August 2020.

This work is licensed under a Creative Commons Attribution NonCommercial 4.0 License (CC BY-NC 4.0).

${ }^{\circ}$ Copyright: the Author(s), 2020

Licensee PAGEPress, Italy

Italian Journal of Medicine 2020; 14:247-248

doi:10.4081/itjm.2020.1357
Some journals have expanded their scope to include COVID-19 to gain traction even though their essential nature is different. In addition, some journals seem to prioritize COVID-19 papers, and they sideline other papers. ${ }^{2}$ Besides, it is possible that erroneous research is published in the din. ${ }^{3}$ This could have severe implications for human lives as retractions by prestigious medical journals are already happening.

While this situation raises some difficult questions on the publication front, it has also increased the noise level, thereby rendering it difficult for the medical researchers to filter out irrelevant research papers. ${ }^{4}$ The problem lies in the sheer volume of papers that is evident from different databases. Though many search engines employ advanced search algorithms, it poses a unique challenge to the medical researchers and practitioners who seek current information on this pandemic. ${ }^{4}$ It becomes a challenge for the frontline stakeholders to segregate research that is actually related to COVID-19 treatment and management from the contrived research. This trend also may raise a question on the quality as many researchers were working from home.

This is the beginning of a potential problem in the realm of research related to COVID-19, as many more papers would be submitted soon. Journals could intervene to reduce the noise created by contrived research by following protocols. The manuscripts should be subject to a thorough review process to ensure a quality review and reduce the pressure on editors and reviewers. The scope of the journals must be tightly defined to avoid unnecessary publications with the COVID-19 tag. It is time to kill the overdrive and active promotion of COVID-19 research by journals that could be stopped with immediate effect. These steps would reduce the inorganic growth in COVID-19 research and ensure that relevant and recent research on the virus is available to the field researchers.

\section{References}

1. Donna G. Publishing in the time of COVID-19. MSK Library Blog; 2020. Available from: https://library. mskcc.org/blog/2020/04/publishing-in-the-time-ofcovid-19/ Accessed: July 28, 2020. 
2. Cochran A. What will we learn about scholarly publishing as a result of COVID-19?. The Scholarly Kitchen; 2020. Available from: https://scholarlykitchen.sspnet. org/2020/04/28/what-will-we-learn-about-scholarlypublishing-as-a-result-of-covid-19/ Accessed: July 28, 2020.

3. Erdek MA. Ethical responsibility in publishing research results on Covid-19 treatments. The Hastings
Center; 2020. Available from: https://www.thehastingscenter. org/ethical-responsibility-in-publishing-research-results-on-covid-19-treatments/ Accessed: July $28,2020$.

4. Brainard J. Scientists are drowning in COVID-19 papers. Can new tools keep them afloat?. Science; 2020. Available from: http://acdc2007.free.fr/drowningcovidpapers.pdf Accessed: July 28, 2020. 